\title{
Lazer Kaynaklı HSLA Sac Malzemelerde Geri Esnemenin Deneysel Araştırılması
}

\author{
Kadir Aydın ${ }^{1 *}$, İbrahim Karaağaç ${ }^{2}$ \\ ${ }^{1}$ Kütahya Dumlupınar Üniversitesi, Simav Meslek Yüksekokulu, Kütahya, Türkiye (ORCID: 0000-0001-5701-8058) \\ 2 Gazi Üniversitesi, Teknoloji Fakültesi, İmalat Mühendisliği Bölümü, Ankara, Türkiye (ORCID: 0000-0001-6727-3650)
}

(İlk Geliş Tarihi 26 Ağustos 2019 ve Kabul Tarihi 27 Eylül 2019)

(DOI: 10.31590/ejosat.611073)

ATIF/REFERENCE: Aydın, K. \& Karaağaç, İ. (2019). Lazer Kaynaklı HSLA Sac Malzemelerde Geri Esnemenin Deneysel Araştırılması. Avrupa Bilim ve Teknoloji Dergisi, (17), 29-37.

\section{$\ddot{O} z$}

$\mathrm{Bu}$ çalışmada farklı güç parametrelerinde lazer kaynağı ile birleştirilen HSLA300 sac malzemelerin bükülme operasyonu sonrası geri esneme davranışına etki eden parametreler deneysel araştırılmıştır. Kaynak parametresi olarak kaynak gücü (1300, 1400 ve 1500 watt), proses parametresi olarak da kalıp açısı $(15,30,45,60$ ve 75 derece) ve ütüleme süresi $(0,10$ ve 20 saniye $)$ deney parametreleri olarak belirlenmiştir. Kaynaklı numunelerde kaynak bölgesindeki ani soğumaya bağlı olarak yüksek miktarda martenzit fazı gözlemlenmiştir. Ancak kaynak gücünün artmasıyla birlikte HSLA yapısındaki karbon ve mangan miktarının az olmasından dolayı sertlik miktarında ve geri esneme açısında azalma meydana gelmiştir. Deneysel çalışmalarda da lazer kaynak gücünün 100 watt artmasıyla geri esneme açısının ortalama 0,15 derece azaldığı gözlenmiştir. Kalıp açısındaki 15 dereceden 45 derece açıya kadar olan artışın bükme operasyonlarında geri esneme açısını ortalama 0,14 derece arttırdığı, 45 derece açıdan 75 derece açıya kadar artışın bükme operasyonlarında geri esneme açısını ortalama 0,52 derece azalttığı gözlemlenmiştir. Ütüleme süresinin 10 saniye artmasıyla geri esneme açısının ortalama 0,14 derece azaldığı belirlenmiştir.

Anahtar Kelimeler: Lazer kaynağı, Geri esneme, HSLA.

\section{The Experimental Investigation of Springback in Laser Welded HSLA Sheet Materials}

\begin{abstract}
In this study, the parameters that affect the springback behavior of HSLA300 sheet materials bonded with laser welding at different power parameters were investigated experimentally. Welding parameters (1300, 1400 and 1500 watts), die angle (15, 30, 45, 60 and 75 degrees) and holding time (0,10 and 20 seconds) were determined as test parameters. A high amount of martensite phase was observed in welded samples due to sudden cooling in the weld zone. However, as the welding power increased, the amount of carbon and manganese in the HSLA structure was reduced, resulting in a decrease in the hardness amount and the bending angle. In experimental studies, it was observed that the springback angle decreased by 0.15 degrees with an increase of 100 watts of laser welding power. It has been observed that the increase in the die angle from 15 degrees to 45 degrees increases the bending angle in the bending operations by an average of 0.14 degrees. It was determined that the springback angle decreased by 0.14 degrees with an increase of 10 seconds holding time.
\end{abstract}

Keywords: Laser welding, Springback, HSLA.

\footnotetext{
* Sorumlu Yazar: Kütahya Dumlupınar Üniversitesi, Simav Meslek Yüksekokulu, Kütahya, Türkiye, ORCID: 0000-0001-5701-8058, kadir.aydin@dpu.edu.tr
} 


\section{Giriş}

Kaynak yapmak için kullanılan enerji kaynaklarından bir tanesi olan lazer ışınının diğer enerji kaynaklarından farklarından en önemlisi, kolaylıkla parça yüzeyinde istenilen noktaya yönlendirilebilmesidir. Bu sayede kaynak yapılacak bölgeye arzu edilen miktarda enerji yerel olarak uygulanabilmektedir. Lazer üretecinden çıkan yoğun enerjinin farklı optik malzemeler vasitasıly malzemelerin birleşme bölgesine odaklanarak bu bölgenin aşırı ısınma sonrasında eriyip iki malzemenin birleşmesi lazer kaynağı olarak adlandırılmaktadır (Jokinen, 2004). Lazer kaynağı, ergitme kaynak yöntemleri içerisinde yer almakta olup geleneksel ergitme kaynak yöntemlerine göre önemli farklılıklar göstermektedir. Lazer kaynağı geleneksel kaynak yöntemleriyle kıyaslandığında, kalın metalik parçalarının çok düşük ısı girdisi ile birleştirilmesini sağlaması ile ön plana çıkmaktadır (Pang ve ark., 2008). Ayrıca lazer ışınının temiz bir enerji kaynağı olması, kaynak işleminin dolgu malzemesi olmadan da gerçekleştirilebilmesi, kaynak hızının yüksek olması, lazer kaynağının otomasyona elverişli olması, benzer veya farklı malzemelerin birleştirilebilmesi lazer kaynağının diğer kaynak yöntemlerine göre önemli avantajlarıdır (Irving, 1997). Lazer üreten cihaz ve ışın iletimini sağlayan sistemin yüksek kurulum maliyeti ise lazer kaynağının en önemli dezavantajı olmaktadır (Karaaslan ve ark., 1998).

Sac metal şekillendirme operasyonları sonrası gözlemlenen geri esneme, şekillendirme işleminin akabinde yük boşaltımı esnasında bir sac malzemenin şeklinin elastik gerilmelerden dolayı değişime uğraması olarak tanımlanmaktadır (Schuler, 1998). Geri esneme davranışı şekillendirilen parçanın ölçüsel doğruluğunu etkilemekte olup sac şekillendirme operasyonlarında istenmeyen bir davranıştır. Geri esnemeye maruz kalan parça, şekillendirme sonrası boyutsal olarak istenilen ölçülerde olmadığından dolayı montaj sırasında problemlerle karşılaşılmaktadır (Karaağaç ve ark., 2019). Sac metal şekillendirme operasyonlarında geri esneme davranışını malzemenin kalınlığı, ütüleme süresi, malzemenin hadde yönü, baskı kuvveti, bükme açısı, sıcaklık, zımba radyüsü, kalıp boşluğu gibi malzeme ve proses parametreleri etkilemektedir (Tekaslan ve ark., 2006). Lazer kaynağı geleneksel kaynak yöntemleriyle kıyaslandığında yüksek miktarda enerjinin rahat bir biçimde odaklanabilmesi ve lazer ışının kolaylıkla yönlendirilebilmesi sebebiyle son yıllarda endüstride tercih edilmektedir. Otomotiv üreticileri azalan enerji kaynakları ve artan çevre kirliliği problemlerinden dolayı yüksek dayanım/düşük ağırlık özelliklerine sahip HSS ailesine mensup yüksek dayanımlı düşük alaşımlı (HSLA) çeliklerini tercih etmektedir. Souza ve Rolfe yaptıkları çalışmada çift fazlı (DP), üç fazlı (TRIP) ve yüksek dayanımlı düşük alaşımlı (HSLA) çelik malzemelerinin baskı plakası kuvveti, sürtünme etkisi ve zımba radyüsü parametrelerinin geri esneme miktarına etkisini sonlu elemanlar methodunu kullanarak araştırmışlardır. Yapılan çalışmada geri esnemeye en az etki eden parametrenin zımba radyüsü olduğu belirlenmiştir. Baskı plakası kuvveti ve sürtünme etkisinin artmasıyla geri esnemenin azaldığı tespit edilmiştir (De Souza ve Rolfe, 2013). Panda ve Pawar zımba açısı, kalıp boşluğu, ön bükme işlemi ve hadde yönünün geri esnemeye etkisini deneysel ve sonlu elemanlar yöntemiyle araştırmışlardır. Çalışma sonucunda geri esnemeye en büyük etkinin zımba açısı ve kalıp boşluğu parametrelerinin olduğu gözlemlenmiştir (Panda ve Pawar, 2018). Mkaddem ve Saidane HSLA sac malzemeyi kenar bükme yöntemiyle şekillendirip geri esneme davranışlarını deneysel ve sonlu elemanlar yöntemiyle araştırmışlardır. Deneysel çalışmalar sonunda zımba radyüsünün geri esnemeyi belirleyen önemli bir parametre olduğu anlaşılmıştır. Sonlu elemanlar yöntemiyle deneysel çalışmaların birbirini doğruladığı gözlemlenmiştir (Mkaddem ve Saidane, 2007). Dai ve diğerleri şekillendirme sonrasında malzemede oluşan hasarın geri esnemeye etkisini geliştirdikleri bir matematiksel model ile araştırmışlardır. Çalışmada HSLA sac malzeme ve U şekillendirme yöntemi kullanmışlardır. Çalışma sonunda sertleşme üssünün, sürtünme katsayısının, şekillendirme kuvvetinin ve hasarın geri esnemeye önemli etkilerinin olduğu tespit edilmiştir (Dai ve ark., 2017). Geri esnemenin araştırıldığı diğer bir çalışmada Ghaei ve diğerleri doğrusal olmayan elastik yükleme ve boşaltma davranışını göz önünde bulundurarak, ileri yüksek mukavemet çeliklerinin geri esneme simülasyonunu yapmışlardır. Yükün boşaltılmasından sonra malzemenin doğrusal olmayan plastik deformasyon bölgesinin içine doğru esnediğini, yükleme üzerine ise malzemenin boşaltmanın aksine doğrusal olmayan elastik bölgeye doğru ivmelendiğini belirlemişlerdir (Ghaei ve ark., 2015).

Lazer kaynağı kullanılarak birleştirilen HSLA sac malzemelerde literatürde çeşitli araştırmalar da yapıllmıştır. Oñoro ve Ranninger lazer kaynağı ile birleştirilmiş HSLA sac malzemelerin yorulma davranışını araştırmışlardır. Çalışma sonunda yorulma sınırının 260 MPa olduğu tespit edilmiştir. Ayrıca çatlak başlangıcının ergime bölgesi ve ergime bölgesi ile isı tesiri altında kalan bölge arasında gerçekleştiği gözlemlenmiştir (Onoro ve Ranninger, 1997). Lun ve diğerleri ise yaptıkları çalışmada DP, TRIP ve HSLA çeliklerini farklı kombinasyonlarda fiber lazer kaynağı ile birleştirmiş mekanik özellikleri ve mikroyapıyı araştırmışlardır. Çalışmada DP ve HSLA malzemelerin kalınlığı aynı, TRIP çeliğ̈inin kalınlığı ise daha fazla seçilmiştir. Yapılan çalışma sonucunda DP ve HSLA erime bölgelerinde benzer sertlikte martenzit bulunduğu saptanmıştır. Çekme deneylerinde sünek şekillenmenin güçsüz olan malzeme tarafına doğru gerçekleştiği tespit edilmiştir (Lun ve ark., 2017).

Literatürde çoğunlukla otomotiv sektörü başta olmak üzere çok sayıda sektörde sıklıkla kullanılan HSLA sac malzemelerin lazer kaynağı ile birleştirilmesi ve birleştirilen bu yapının mekanik özellikleri araştırılmıştır. Ayrıca sadece HSLA malzemelerin bükme yöntemiyle şekillendirilme çalışmalarının da yaygın olarak araştırıldığı tespit edilmiştir. Ancak, lazer kaynağı kullanılarak birleştirilen HSLA sac malzemelerde kaynağın şekillendirilebilirliğe ve geri esneme davranışına etkilerinin araştırılmadığı belirlenmiştir. Bu çalışmada lazer kaynağı ile birleştirilen HSLA sac malzemelerin bükme operasyonu sonrası şekillendirilebilirliğine ve geri esneme davranışına etki eden kaynak ve proses parametrelerinin belirlenmesi amaçlanmıştır. 
Bu çalışmada, öncelikle aynı hadde yönüne sahip iki adet HSLA300 sac malzeme lazer kaynağı kullanılarak birleştirilmiştir. Çalışmanın devamında birleştirilen bu sac malzemelerin V bükme yöntemiyle bükülmesi ile şekillendirilebilirlik ve geri esneme davranışına kaynak parametrelerinin ve proses parametrelerinin etkisinin deneysel araştırılması amaçlanmıştır.

\section{Materyal ve Metot}

\subsection{Malzeme}

Yüksek mukavemetli düşük alaşımlı çelikler (HSLA) yumuşak ferrit matris içinde dağılmış sert karbür tanelerden oluşan mikroyapıları içermektedir (Erdoğan, 2003; Türkmen ve Gündüz, 2011). Sürekli akma davranışı, deformasyon sertleşmesinin yüksek olması, iyi işlenebilirlik ve yüzey kalitesi gibi özelliklerinden ötürü çift fazlı çeliklerle kıyaslanmaktadırlar. Bu özelliklerinden dolayı HSLA malzemeler kullanım yerlerinde üstün performans göstermektedirler. HSLA çelikleri, iyi şekillendirilebilirliğinden ötürü otomotiv endüstrisinde yaygın kullanım alanına sahip olan malzemelerdir. Özellikle otomotiv endüstrisinde bu malzemelerin seçilmesinin nedeni, yüksek dayanım/ağırlık oranları ile araç hafifletme çalışmalarında yakıt tüketimini azaltmaları ile enerji tasarrufu sağlamaları ve karbon emisyonunun azaltılması ile de çevreye olan katkılarından dolayı büyük öneme sahip olmalarıdır (Türkmen ve Gündüz, 2011).

Deney malzemesi olarak soğuk haddelenmiş 1.2 mm kalınlığında HSLA300 çelik sac malzeme kullanılmıştır. Deney malzemesinin mekanik özelliklerinin belirlenmesi için çekme ve sertlik ölçme testi yapılmıştır. Malzemenin testlerden elde edilen mekanik özelliklerin ortalama değerleri Tablo 1'de verilmiştir. Malzemenin kimyasal kompozisyonunun belirlenmesi için kimyasal spektrometre testi yapılmıştır. Kimyasal spektrometre ile analiz sonuçları da Tablo 2'de verilmiş̧ir.

Tablo 1. HSLA sac malzemenin mekanik özellikleri

\begin{tabular}{c|c|c|c|c}
\hline $\begin{array}{c}\text { Akma dayanımı } \\
(\mathbf{M P a})\end{array}$ & $\begin{array}{c}\text { Çekme dayanımı } \\
\mathbf{( M P a )}\end{array}$ & $\begin{array}{c}\text { Uzama } \\
\mathbf{( \% )}\end{array}$ & $\begin{array}{c}\text { Elastisite modülü } \\
\mathbf{( G P a )}\end{array}$ & $\begin{array}{c}\text { Sertlik } \\
(\text { Vickers) }\end{array}$ \\
\hline 314,231 & 396,357 & 32,182 & 182,929 & 96 \\
\hline
\end{tabular}

Tablo 2. HSLA sac malzemenin kimyasal kompozisyonu(\% ăg.)

\begin{tabular}{c|c|c|c|c|c|c}
\hline & $\mathbf{C}$ & $\mathbf{M n}$ & $\mathbf{C r}$ & $\mathbf{C u}$ & $\mathbf{N b}$ & $\mathbf{F e}$ \\
\hline HSLA & 0,068 & 0,254 & 0,034 & 0,03 & 0,03 & Kalan \\
\hline
\end{tabular}

\subsection{Lazer Kaynak İşlemi ve Kaynak Parametreleri}

HSLA300 sac malzeme su jeti ile 0 derece hadde yönünde kesilerek 40x20 mm boyutlarında kesilerek hazırlanmıştır. Malzemeler IPG YLR-6000 fiber lazer kaynağı kullanılarak alın kaynağı yöntemiyle birleştirilmiştir. Kesilerek hazırlanan malzemelerin lazer kaynak gücünün mikroyapıya, sertliğe ve geri esnemeye etkilerinin belirlenebilmesi için üç farklı lazer kaynak gücü ile lazer kaynak işlemi gerçekleştirilmiştir. Kaynak parametreleri Tablo 3 'te verilmiştir.

Tablo 3. Lazer kaynak parametreleri

\begin{tabular}{c|c|c|c|c}
\hline & $\begin{array}{c}\text { Kaynak gücü } \\
\text { (watt) }\end{array}$ & $\begin{array}{c}\text { Kaynak hızı } \\
(\mathbf{m m} / \mathbf{d k})\end{array}$ & $\begin{array}{c}\text { Lazer çapı } \\
\text { (mikron) }\end{array}$ & $\begin{array}{c}\text { Koruyucu } \\
\text { gaz }\end{array}$ \\
\hline Lazer kaynak parametresi 1 & 1300 & 2000 & 400 & Argon \\
\hline Lazer kaynak parametresi 2 & 1400 & 2000 & 400 & Argon \\
\hline Lazer kaynak parametresi 3 & 1500 & 2000 & 400 & Argon \\
\hline
\end{tabular}

\subsection{Deney Parametreleri ve Deneysel Çalıșma Ortamı}

Lazer kaynağı ile birleştirilen HSLA-HSLA malzeme çiftinin şematik görüntüsü Şekil 1'de verilmiştir. Deneysel çalışmalar da bilgisayar kontrollü deney düzeneği vasıtasıyla gerçekleştirilmiştir. Deney düzeneğinde bükme kuvveti, bükme hızı ve ütüleme süresi 
değerlerinin kontrolü programa girilen veriler vasıtasıyla elektronik olarak sağlanmaktadır. Deneysel çalışmalarda her bir deney üçer defa tekrar edilmiştir. Deneysel çalışma ortamı Şekil 2'de verilmiştir.

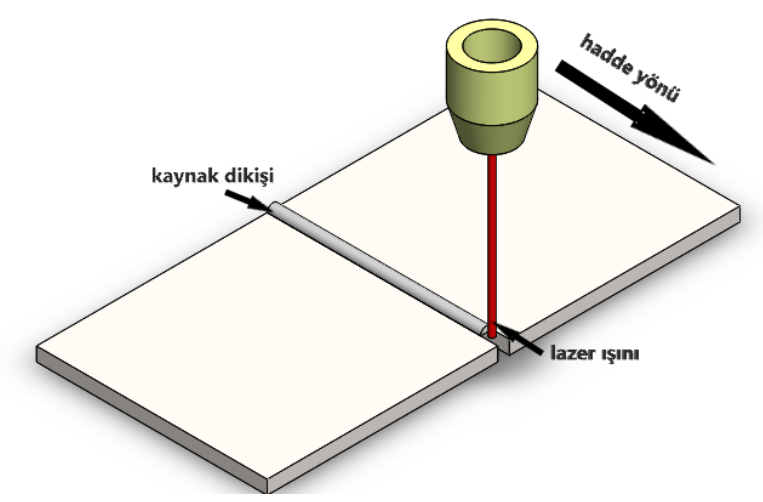

Şekil 1. Lazer kaynakl malzemenin şematik görünümü

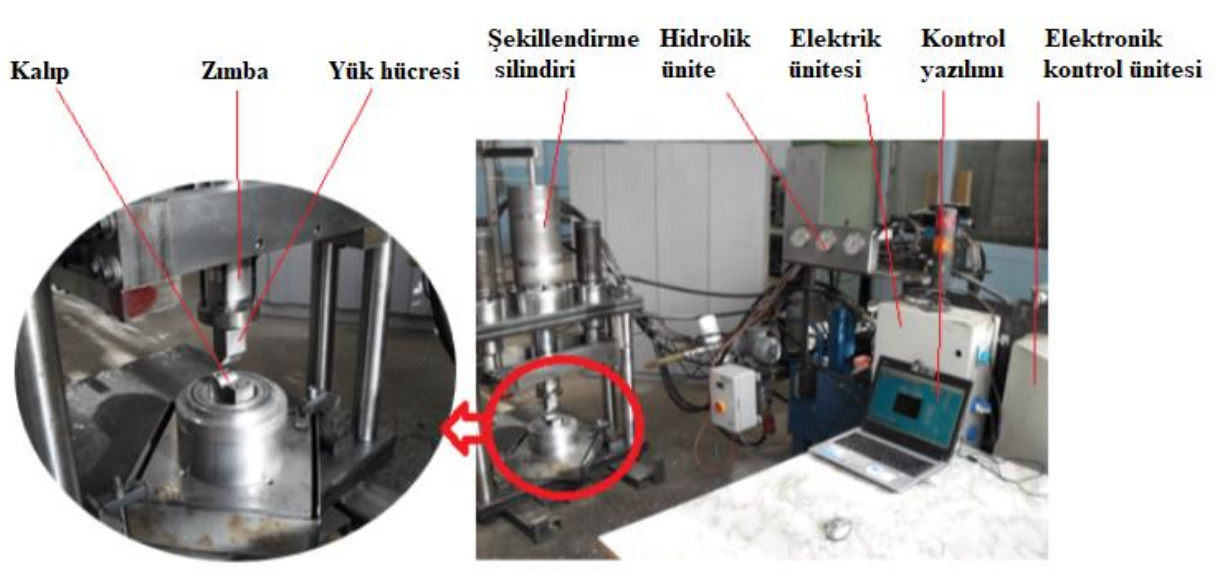

(a)

(b)

Şekil 2. Deney düzeneğinin görüntüsü; a) detay görünüm, b) genel görünüm

Deneysel çalışmalarda; kalıp açısı, ütüleme süresi ve lazer kaynak gücü deney parametresi olarak seçilmiştir. Deney parametreleri ve parametre değerleri Tablo 4'te verilmiştir.

Tablo 4. Deneysel çalışma parametreleri ve parametre dĕgerleri

\begin{tabular}{c|c}
\hline Deney parametresi & Parametre değerleri \\
\hline Kalıp açısı (derece) & $15,30,45,60$ ve 75 \\
\hline Ütüleme süresi (saniye) & 0,10 ve 20 \\
\hline Lazer kaynak gücü (watt) & 1300,1400 ve 1500 \\
\hline Malzeme & Kaynaksı HSLA, Kaynaklı HSLA \\
\hline
\end{tabular}

Deneysel çalışmada şekillendirme kuvvetini hesaplamak amacıyla Eş.1 kullanılmıştır (Handbook ASM, 1988). Eş.1'de verilen; L şekillendirme kuvveti, 1 bükme uzunluğu, k kalıp açıklık faktörü, t sac kalınlığı, S çekme gerilmesi, s kalıp açıklığının genişliği olarak tanımlanmıştır.

$$
L=\frac{l \cdot t^{2} \cdot k \cdot S}{S}
$$




\subsection{Geri esneme davranışı ve geri esnemenin ölçümü}

Bükme operasyonlarında, malzemelerin elastikiyet sınırı aşılmakta, ancak maksimum çekme gerilmeleri aşılamamaktadır. Bu nedenle, bükme operasyonları sonrası malzeme sahip olduğu elastik gerilmelerden dolayı geri eski şeklini almaya çalışmakta ve şekil bükme açısından sapmaktadır. Malzemenin göstermiş olduğu bu davranış geri esneme olarak tanımlanmaktadır. Sac malzemenin ileriye doğru esnemesi de negatif geri esneme veya ileri esneme olarak tanımlanmaktadır (Thipprakmas ve Rojananan, 2008). Şekil 3'te geri esnemenin şematik gösterimi ve geri esnemenin CMM (koordinat ölçme makinesi) ile ölçümü verilmiştir.

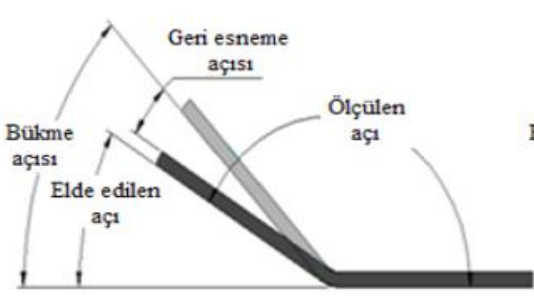

(a)

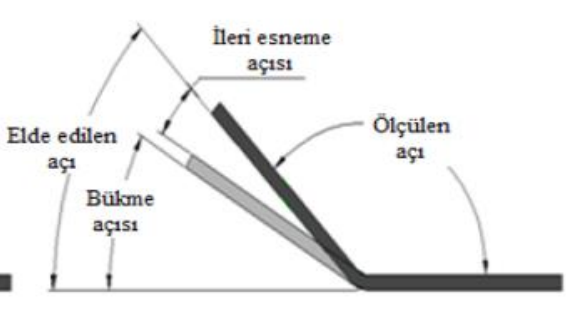

(b)

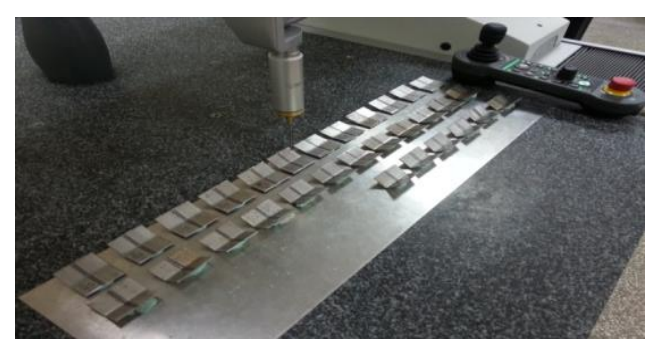

(c)

Şekil 3. Bükme prosesi (a) geri esneme, (b) negatif geri esneme/ileri esneme; (c) CMM ile geri esnemenin ölçümü

V bükme yöntemiyle bükülerek şekillendirilen malzemelerin geri esneme ölçümü bilgisayarlı koordinat ölçme (CMM) cihazı ile yapılmıştır. Öncelikli olarak malzemeler bir sac plaka üzerine deforme edilmeden yapıştırılmıştır. Geri esneme açısını ölçme işlemi ise CMM cihazının probunun bükülen parçanın her bir yüzeyine dört noktadan dokundurulup birer düzlem elde edildikten sonra elde edilen iki düzlem arasında kalan açının kalıp açısından çıkarılmasıyla elde edilmiştir.

\subsection{Mikroyapı İncelemesi}

Kaynak esnasında malzemenin iç yapısında oluşan değişikliklerin değerlendirilmesi amacıyla birleştirilen parçaların mikroyapıları da incelenmiştir. Bu amaçla kaynaklı bölgeyi içerecek şekilde hassas kesme cihazı ile kesilen numuneler bakalitleme işlemi için bakalite alınmış ve parlatma işleminden sonra alkol ile yıkandıktan sonra kurutulmuştur. Numuneler son aşamada da \%3'lük nital çözeltisiyle 5 saniye dağlama işlemine tabi tutulmuştur. Dağlanan numunelerin görüntüleri NIKON marka optik mikroskop kullanılarak elde edilmiştir.

\section{Araștırma Sonuçları ve Tartışma}

Deneysel çalışmalardan elde edilen sonuçlar lazer kaynağı ve proses parametrelerinin geri esnemeye etkilerine göre değerlendirilmiştir. Lazer kaynağında kullanılan kaynak güç parametresinin geri esnemeyi doğrudan etkileyen ve malzemenin mikroyapısında da önemli değişikliklere yol açan parametre olduğu gözlemlenmiştir. Kaynaklı parçalarda mikroyapı incelemesi; erime bölgesi, 1sı tesiri altındaki bölge ve ana metal olmak üzere üç bölgede incelenmiştir.

Lazer kaynaklı numunelerde kaynak bölgesinde ani soğumaya bağlı olarak martenzit yapı gözlenmiştir. Kaynak bölgesinde oluşan sıcaklık malzemenin ergime sıcaklığının üzerindedir. Bundan dolayı kaynak bölgesinin tamamına yakını martenzit fazından oluşmaktadır. Kaynak bölgesinden uzaklaştıkça oluşan sıcaklıkta azalma meydana gelmektedir Kaynak bölgesine yakın 1sı tesiri altındaki bölgede $\mathrm{Ac}_{1}$ ve $\mathrm{Ac}_{3}$ çizgileri arasında \%100 ostenitleşme gerçekleşmemesinden dolayı ferrit fazında artış, martenzit fazında ise azalma meydana gelmiştir. Kaynak bölgesinden uzaklaştıkça sıcaklık Ac ç̧izgisinin altına düşmektedir. Bu sebeple ana metale yakın bölgede yarı kararlı temperlenmiş martenzit fazı ortaya çıkmıştır (Dong ve ark., 2014). Farklı güç parametrelerinde lazer kaynağı ile birleştirilmiş HSLA çelik sac malzemelerin optik mikroskop görüntüleri Şekil 4-6'da verilmiştir.
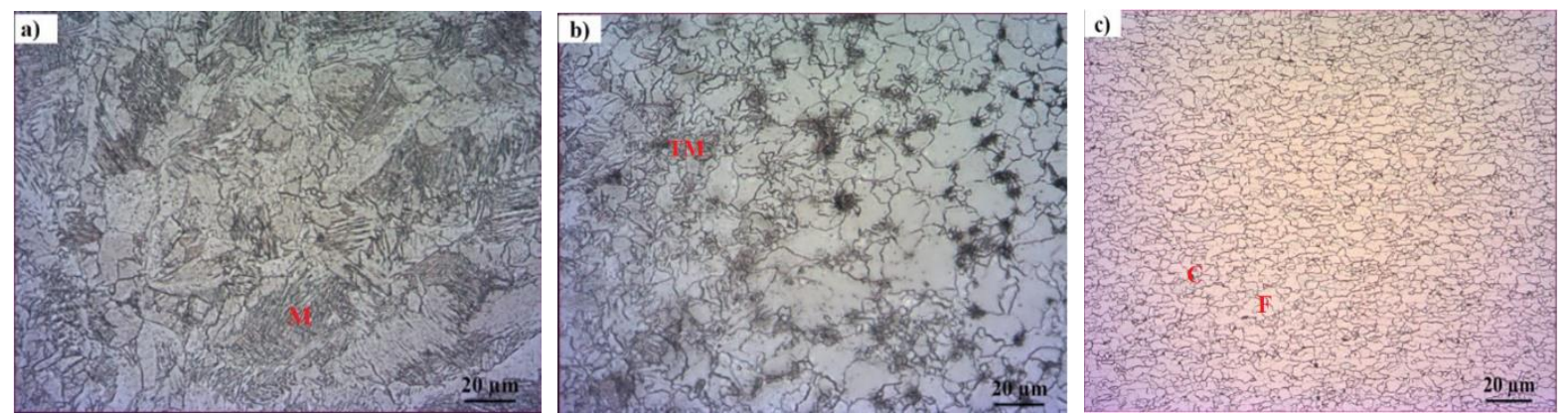

Şekil 4. 1300 watt lazer kaynak gücü; (a) erime bölgesi, (b) ısı tesiri altındaki bölge (ITAB), (c) ana metal

(M: martenzit, F: ferrit, C: karbür alaşımı, TM: temperlenmiş martenzit) 

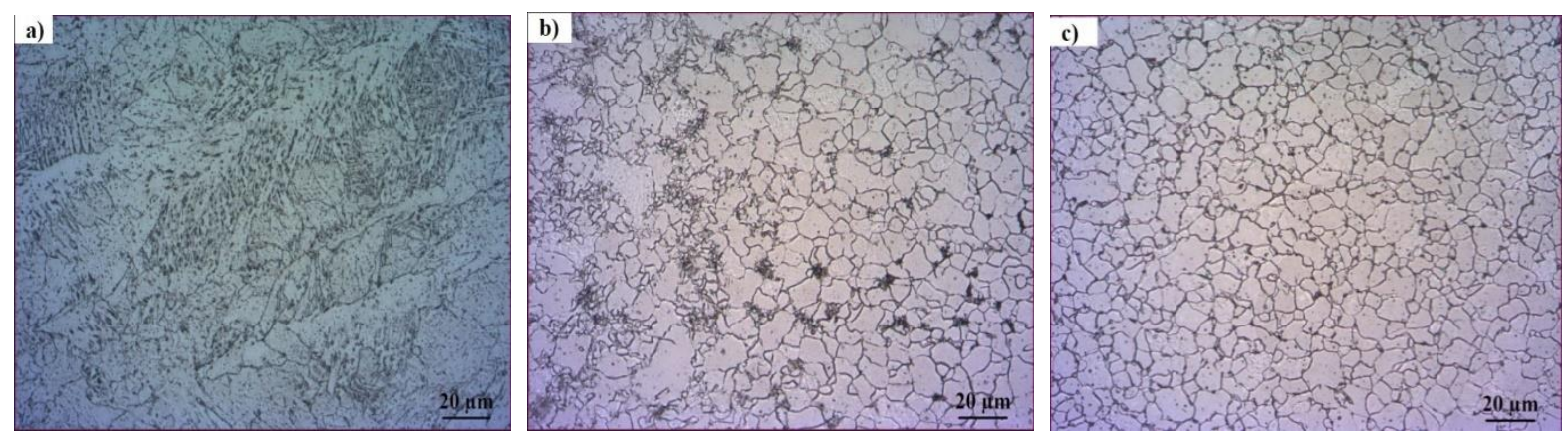

Şekil 5. 1400 watt lazer kaynak gücü; (a) erime bölgesi, (b) ısı tesiri altındaki bölge (ITAB), (c) ana metal
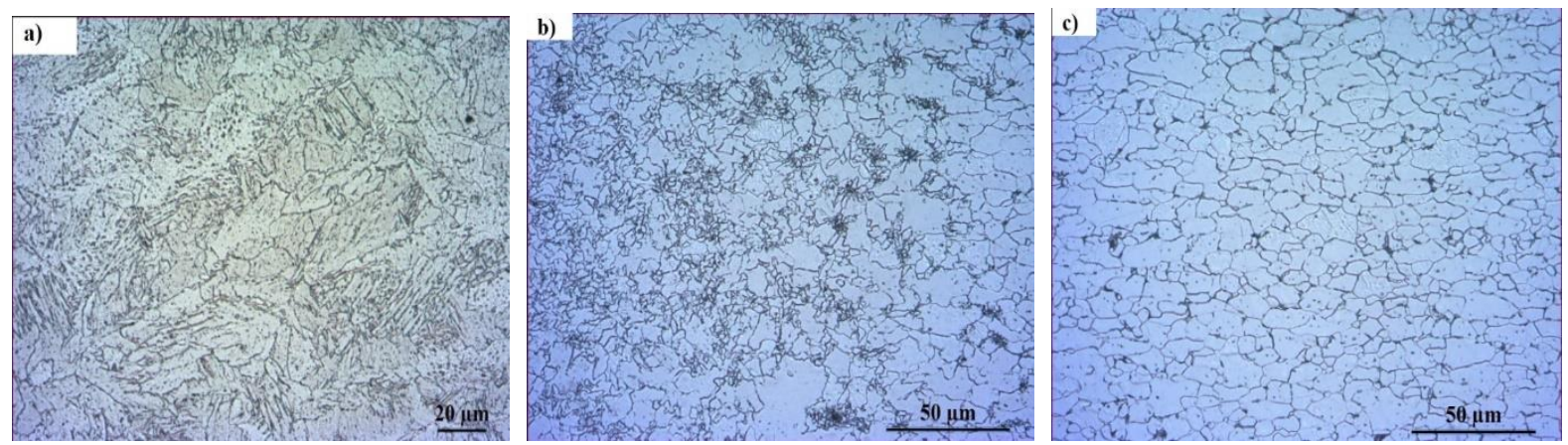

Şekil 6. 1500 watt lazer kaynak gücü; (a) erime bölgesi, (b) ısı tesiri altındaki bölge (ITAB), (c) ana metal

Numunelerde kaynak bölgesinde martenzit artışından dolayı ana metal ve ısı tesiri altında kalan bölgeye kıyasla daha yüksek sertlik değerleri tespit edilmiştir. Kaynak bölgesinden uzaklaş̧ıkça malzemede $\% 100$ ostenitleşme oluşamamasından dolayı sertlik değerinde ana metale doğru azalma gözlemlenmiştir. Kaynak gücünün artmasıyla kaynak bölgesi ile 1sı tesiri altındaki bölgenin genişlemesine karşılık martenzit fazının oluşumuna neden olan karbon ve mangan elementlerinin HSLA malzeme yapısında düşük miktarda bulunmasından dolayı bu bölgelerde martenzit dönüşümü tam olarak gerçekleşememiştir (Khan ve ark., 2009). Bu durum da kaynak gücünün artmasıyla birlikte özellikle erime bölgesi ve 1sı tesiri altında kalan bölgede sertliğin azalmasına sebep olmuştur. Sertlik artışı geri esneme açısını arttırırken sertlik azalması da geri esneme açısını azalmaktadır (Karaağaç, 2017). Kaynak gücünün artmasıyla sertlik değerlerinde görülen azalmayla birlikte geri esneme açısında da azalma tespit edilmiştir. Şekil 7'de kaynak merkezinden uzaklığa göre sertlikteki değişimi farklı güç parametrelerine göre verilmiştir.

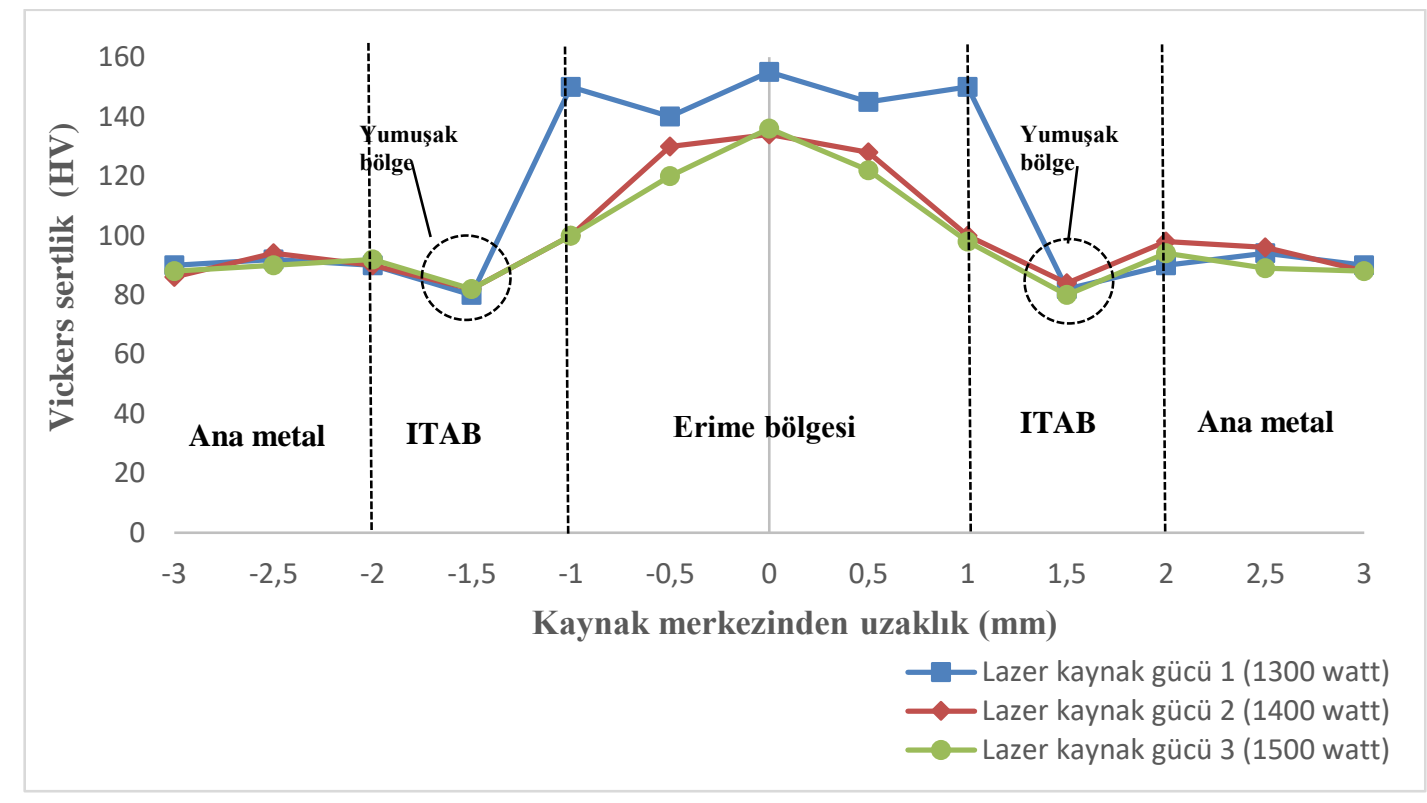

Şekil 7. Lazer kaynakl malzemelerin sertlik değerleri 
Şekillendirme prosesinde zımbanın malzeme üzerinde bekleme zamanı olarak adlandırılan ütüleme süresi geri esnemeyi etkileyen önemli parametrelerdendir (Ahmed ve ark., 2014). Şekillendirme esnasında, ütüleme süresinin artmasıyla birlikte malzemenin şekli sınırlanmaktadır. Malzemenin sınırlanması kalıcı gerilemelerin artmasına sebep olmaktadır. Bu durum geri esneme açısını da azaltmaya yol açmaktadır (Karaağaç, 2017).

Kalıp açısındaki artışa bağlı olarak 45 derece açıya kadar geri esneme açısında artış gözlemlenmiştir. Bu durum açının artmasına bağlı olarak büküm bölgesinde elastik gerilmelerin artmasından kaynaklanmaktadır (Ahmed ve ark., 2014).

Zımbanın kalıp en alt noktasına kadar temas ederek yapmış olduğu bükme işlemlerinde (bottoming bending), sac malzeme kalıp ile zımba arasında preslenmekte ve zımbanın ucu malzemeyi ezmektedir. Büküm çizgisi boyunca bu ezilmeden dolayı sac kalınlığında incelme meydana gelmektedir. Bu durum 15 derece gibi kü̧̈ük açılarda içeri doğru fazla bükülmeye (overbending) neden olmaktadır. Bundan dolayı her iki sac malzeme için de 15 derece büküm açılarında negatif geri esneme (ileri esneme) gözlemlenmiştir. Ancak büküm açısının artması ile birlikte büküm bölgesinde ki gerilme miktarında (sac iç yüzeyinde basma ve sac dış yüzeyinde çekme) artma meydana gelmektedir. Artan bu gerilmeler, fazla bükümün oluşturmuş olduğu ileri esnemenin geri esnemeye dönmesine neden olmaktadır. Kalıp açısının 15 dereceden 30 dereceye artışı ile birlikte ileri esnemenin geri esnemeye dönüştüğü gözlemlenmektedir. Ancak, küçük zımba uç radyüsünün olduğu bükme operasyonlarında gerilmeler sac malzeme üzerinde büküm bölgesinde dar bir alanda toplanmaktadır. Büküm açısının artması ile birlikte bu gerilmelerin sac malzeme üzerinde toplandığı alan daha da daralmaktadır. Bu nedenle kalıp açısının artmasına bağlı olarak geri esneme miktarında azalma meydana gelmektedir. Düşük gerilimli sac malzemelerde 75 derece gibi daha büyük açılarda da bu gerilmeler fazla bükme etkisini aşamayarak malzemede negatif geri esnemenin gözlemlenmesine neden olmuştur (Aydın ve ark., 2019). Şekil 8-10'da kalıp açısı geri esneme ilişkisi farklı güç parametrelerine ve ütüleme sürelerine göre verilmiştir.

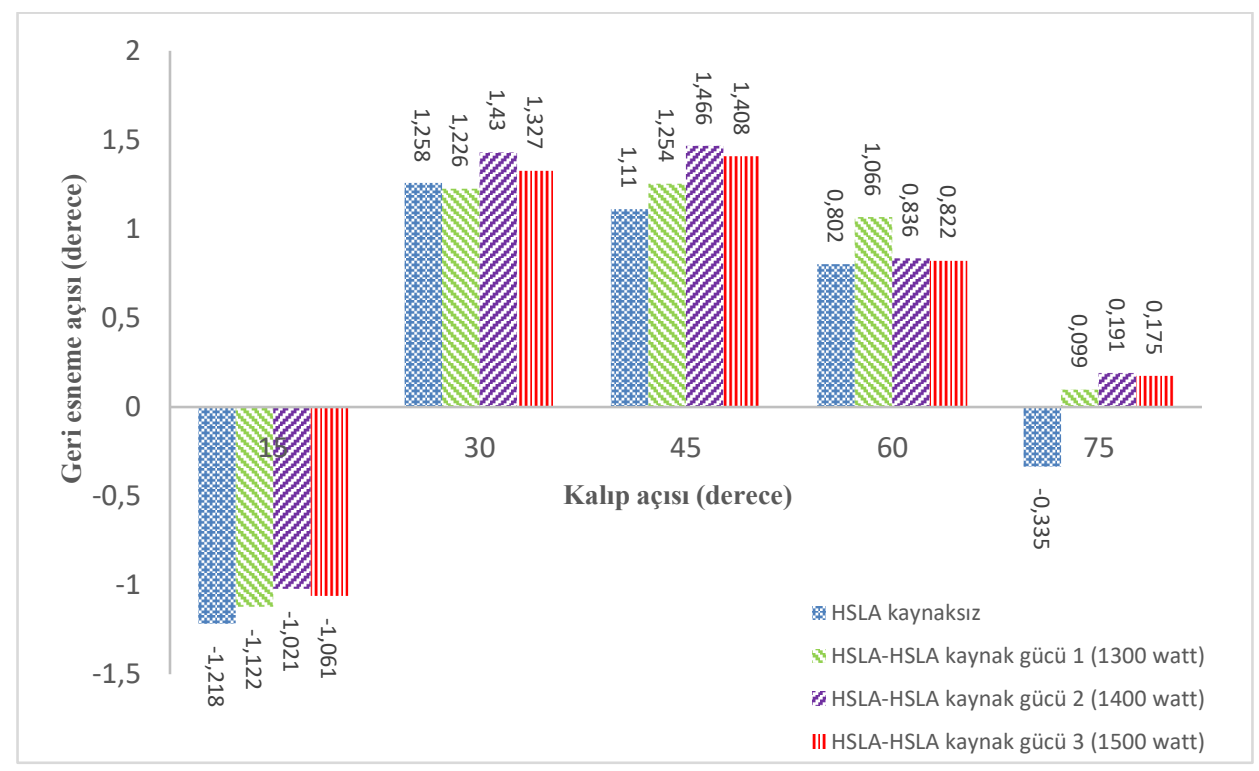

Şekil 8. Geri esneme-kalıp açısı iliş̧kisi, 0 saniye ütüleme süresi 


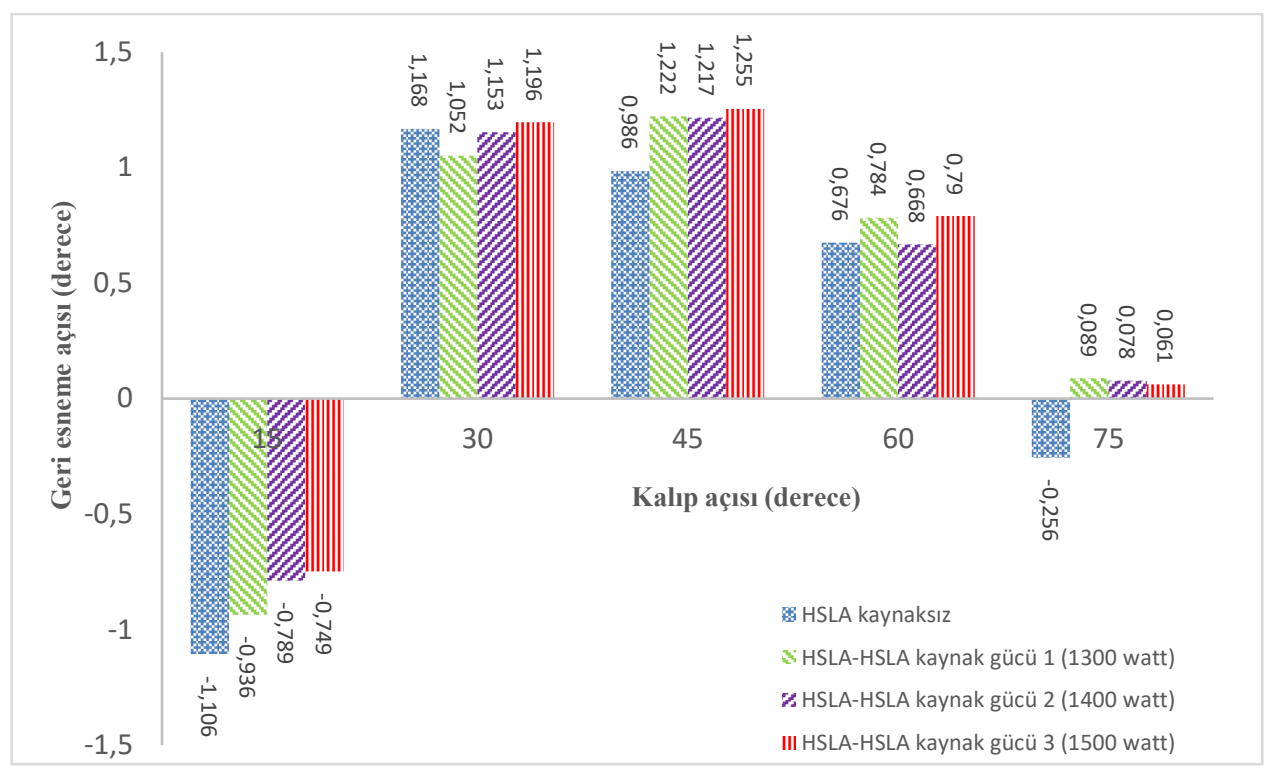

Şekil 9. Geri esneme-kalıp açısı ilişkisi, 10 saniye ütüleme süresi

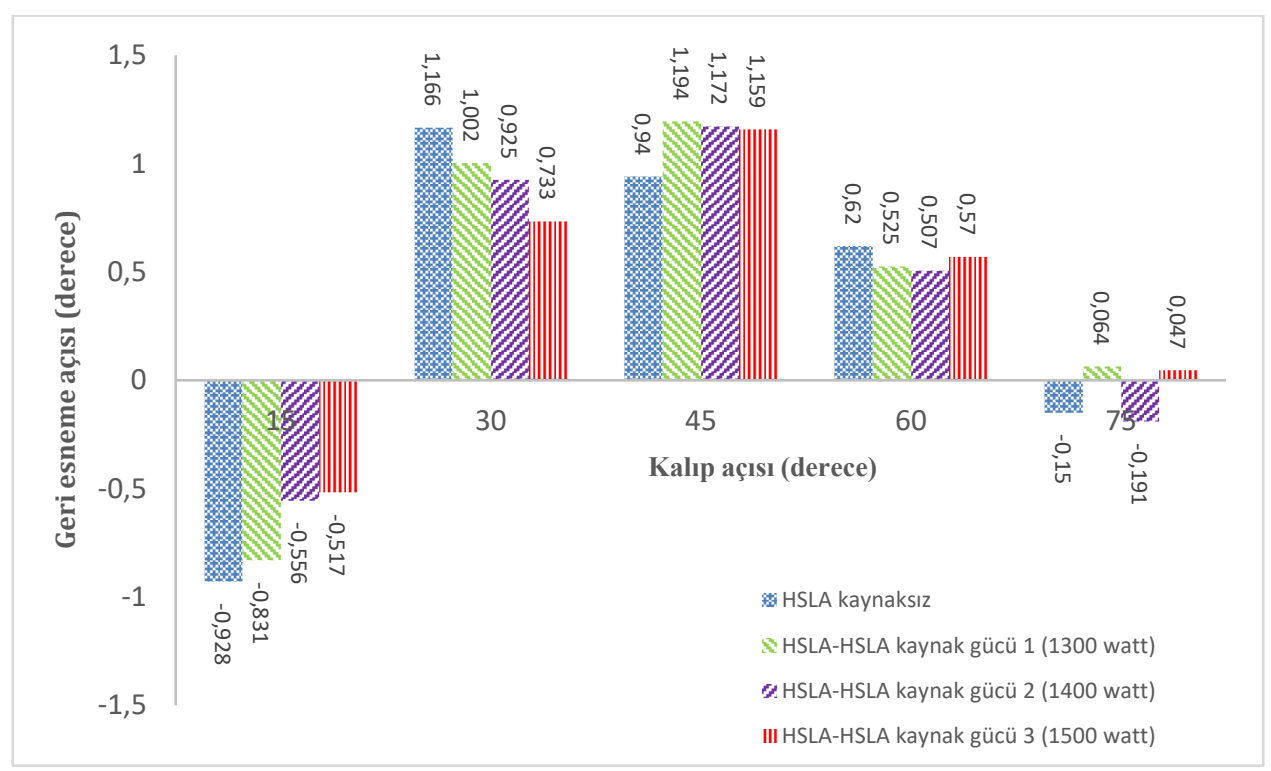

Şekil 10. Geri esneme-kalıp açısı ilişskisi, 20 saniye ütüleme süresi

\section{Sonuç}

Lazer kaynağı güç parametresi ve proses parametrelerinin lazer kaynağı ile birleştirilen parçalarda geri esnemeye etkileri açısından değerlendirilmiştir.

- Lazer kaynak gücünün artmasıyla birlikte geri esneme açısında azalma gözlemlenmiștir. Bu durumun lazer kaynak gücünün artmasıyla beraber sertliğin azalmasından kaynaklanmışıtı. Artan sıcaklıktan dolayı HSLA yapısında martenzit yapıcı karbon ve mangan elementlerinin düşük miktarda bulunmasından kaynaklandığı mikroyapı incelemelerinden elde edilmiştir. Lazer kaynak gücünün 100 watt artmasıyla geri esneme açısının ortalama 0,15 derece azaldığı gözlenmiştir.

- Geri esneme davranışının kalıp açısındaki değişime bağlı olarak da değiştiği tespit edilmiştir. 45 derece kalıp açısına kadar geri esneme açısının ortalama 0,14 derece arttığı, 45 dereceden sonra da geri esneme açısının ortalama 0,52 derece azaldığı gözlemlenmiştir. Geri esneme açısındaki bu artış kalıp açısındaki artışa bağlı olarak büküm bölgesindeki gerilmelerin artmasından kaynaklanmıştır. 45 dereceden sonra da esneme açısının azalması gerilmelerin büküm açısının büyümesi ile dar bir alanda toplanmasından kaynaklanmıştır. 
- Geri esneme davranışına etki eden bir diğer parametre de ütüleme süresi olarak gözlenmiştir. Ütüleme süresinin artması ile birlikte elastik gerilmelerin malzemede sınırlanması nedeniyle bu gerilmeler kalıcı plastik gerilmelere dönüşümektedir. Bu durumda geri esneme açısında azalmaya yol açmıştır. Deneysel çalışmalarda da ütüleme süresinin 10 saniye artışına bağlı olarak geri esneme açısının ortalama 0,14 derece azaldığı belirlenmiştir.

- Kaynaksız tek parça HSLA sac malzemenin bükümünde en büyük geri esneme açısı 1,258 derece, en küçük geri esneme açıs1 0,15 derece elde edilmiştir. Aynı boyutlarda ve aynı hadde yönünde HSLA-HSLA kaynaklı sac malzemenin bükümünde en büyük geri esneme açısı 1,466 derece elde edilirken, en küçük geri esneme açısı 0,047 derece elde edilmiştir. HSLA sac malzemelerin şekillendirilmesinde, lazer kaynaklı parçaların şekillendirilebilirlik açısından ileri düzey şekillendirme kusurlarına sebep olmayacağı ve lazer kaynağı ile birleştirilen sac malzemelerin sorunsuz bir şekilde şekillendirilebileceği gözlemlenmiştir.

\section{Kaynakça}

Ahmed, G. S., Ahmed, H., Mohiuddin, M. V., \& Sajid, S. M. S. (2014). Experimental evaluation of springback in mild steel and its validation using LS-DYNA. Procedia materials science, 6, 1376-1385.

Aydın, K., Karaağaç, İ., \& Uluer, O. (2019). The formability and springback characterization of laser-welded DP-HSLA sheets. Applied Physics A, 125(8), 525.

Dai, H. L., Jiang, H. J., Dai, T., Xu, W. L., \& Luo, A. H. (2017). Investigation on the influence of damage to springback of U-shape HSLA steel plates. Journal of Alloys and Compounds, 708, 575-586.

De Souza, T., \& Rolfe, B. F. (2013). Understanding robustness of springback in high strength steels. International Journal of Mechanical Sciences, 68, 236-245.

Dong, D., Liu, Y., Yang, Y., Li, J., Ma, M., \& Jiang, T. (2014). Microstructure and dynamic tensile behavior of DP600 dual phase steel joint by laser welding. Materials Science and Engineering: A, 594, 17-25.

Erdogan, M. (2003). Effect of austenite dispersion on phase transformation in dual phase steel. Scripta Materialia, 48(5), 501-506.

Ghaei, A., Green, D. E., \& Aryanpour, A. (2015). Springback simulation of advanced high strength steels considering nonlinear elastic unloading-reloading behavior. Materials \& Design, 88, 461-470.

Handbook, A. S. M. (1988). Forming and forging. ASM international, 14, 483.

Irving, B. (1997). Laser beam welding shifts into high gear. Welding journal, 76(11).

Jokinen, T. (2004). Novel ways of using Nd: YAG laser for welding thick section austenitic stainless steel. VTT.

Karaağaç, İ. (2017). The experimental investigation of springback in V-bending using the flexforming process. Arabian Journal for Science and Engineering, 42(5), 1853-1864.

Karaağaç, İ., Önel, T., \& Uluer, O. (2019). The effects of local heating on springback behaviour in v bending of galvanized DP600 sheet. Ironmaking \& Steelmaking, 1-7.

Karaaslan, A., Sönmez, N., \& Topuz, A. (1998). Lazer ile kaynak edilebilirliğin alaşımsız yapı çeliğinde araştırılması, 2. Uluslararası Kaynak Teknolojisi Sempozyumu.

Khan, M. S., Bhole, S. D., Chen, D. L., Biro, E., Boudreau, G., \& Van Deventer, J. (2009). Welding behaviour, microstructure and mechanical properties of dissimilar resistance spot welds between galvannealed HSLA350 and DP600 steels. Science and Technology of Welding and Joining, 14(7), 616-625.

Lun, N., Saha, D. C., Macwan, A., Pan, H., Wang, L., Goodwin, F., \& Zhou, Y. (2017). Microstructure and mechanical properties of fibre laser welded medium manganese TRIP steel. Materials \& Design, 131, 450-459.

Mkaddem, A., \& Saidane, D. (2007). Experimental approach and RSM procedure on the examination of springback in wiping-die bending processes. Journal of Materials Processing Technology, 189(1-3), 325-333.

Onoro, J., \& Ranninger, C. (1997). Fatigue behaviour of laser welds of high-strength low-alloy steels. Journal of Materials Processing Technology, 68(1), 68-70.

Panda, N., Pawar, R. S. (2018). Optimization of process parameters affecting on springback in v-bending process for high strength low alloy steel HSLA 420 using FEA and Taguchi technique. World Academy of Science, Engineering and Technology International Journal of Aerospace and Mechanical Engineering, 12(1), 28-34.

Pang, M., Yu, G., Wang, H. H., \& Zheng, C. Y. (2008). Microstructure study of laser welding cast nickel-based superalloy K418. Journal of Materials Processing Technology, 207(1-3), 271-275.

Schuler GmbH., \& Schuler GmbH. (1998). Metal forming handbook. Springer Science \& Business Media.

Tekaslan, Ö., Şeker, U., \& Özdemir, A. (2006). Determining springback amount of steel sheet metal has $0.5 \mathrm{~mm}$ thickness in bending dies. Materials \& design, 27(3), 251-258.

Thipprakmas, S., \& Rojananan, S. (2008). Investigation of spring-go phenomenon using finite element method. Materials \& Design, 29(8), 1526-1532.

Türkmen, M., \& Gündüz, S. (2011). Martensite morphology and strain aging behaviours in intercritically treated low carbon steel. Ironmaking \& Steelmaking, 38(5), 346-352. 